\title{
Effects of High Salt-Exposure on the Development of Retina and Lens in 5.5-Day Chick Embryo
}

\author{
Yao Chen ${ }^{\mathrm{a}}$ Guang Wang ${ }^{\mathrm{a}}$ Xiao-yu Wang ${ }^{\mathrm{a}}$ Zheng-lai Ma ${ }^{\mathrm{a}}$ You-peng Chen ${ }^{\mathrm{b}}$ \\ Manli Chuaic Karoline von Websky ${ }^{d}$ Berthold Hocher ${ }^{d}$ Xuesong Yanga,e
}

aKey Laboratory for Regenerative Medicine of the Ministry of Education, Division of Histology and Embryology, Medical College, ${ }^{b}$ Department of Infectious Diseases, the first Affiliated Hospital of Jinan University, Guangzhou China; 'Division of Cell and Developmental Biology, University of Dundee, Dundee, DD1 5EH, UK; 'Institute of Nutritional Science, University of Potsdam, Potsdam-Nuthetal, Germany; eInstitute of Fetal-Preterm Labor Medicine, Jinan University, Guangzhou, China

\section{Key Words}

Chick embryos $\bullet$ High osmolarity $\bullet$ Retina $\bullet$ Lens $・$ Pax6

\begin{abstract}
Background/Aims: Excess maternal salt intake during pregnancy may alter fetal development. However, our knowledge on how an increased salt intake during pregnancy influences fetal eye development is limited. In this study, we investigated the effects of high-salt treatment on the developing eyes in chick embryos, especially focusing on the development of the retina and the lens. Methods: 5.5 -day chick embryos were exposed to $280 \mathrm{mosm} / \mathrm{l}(\mathrm{n}=17)$, or $300 \mathrm{mosm} / \mathrm{l}(\mathrm{n}=16) \mathrm{NaCl}$. The treated embryos were then incubated for 96 hours before they were fixed with $4 \%$ paraformaldehyde for $\mathrm{H} \& \mathrm{E}$ staining, whole-mount embryo immunostaining and TUNEL staining. BrdU and PH3 incorporation experiments were performed on the chick embryos after high-salt treatment. RT-PCR analyses were conducted from chick retina tissues. Results: We demonstrated that high-salt treatment altered the size of eyes in chick embryos, induced malformation of the eyes and impaired the development of the lens and the retina. We found an impaired expression of Paired box 6 (PAX6) and neuronal cells in the developing retina as revealed by neurofilament immunofluorescent staining. There was a reduction in the number of BrdU-positive cells and PH3-positive cells in the retina, indicating an impaired cell proliferation with high-salt treatment. High-salt treatment also resulted in an increased number of TUNEL-positive cells in the retina, indicating a higher amount of cell death. RT-PCR data displayed that the expression of the pro-apoptotic molecule nerve growth factor (NGF) in chick retina was increased and CyclinD1 was reduced with high-salt treatment. The size of the lens was reduced and Pax6 expression in the lens was significantly inhibited. High salttreatment was detrimental to the migration of neural crest cells. Conclusion: Taken together, our study demonstrated that high-salt exposure of 5.5-day chick embryos led to an impairment of retina and lens development, possibly through interfering with Pax6 expression.

Copyright (C) 2014 S. Karger AG, Basel

Y. Chen and G. Wang contributed equally to the work.

Berthold Hocher

and Xuesong Yang

Institute of Nutritional Science, University of Potsdam, 14558 Nuthetal, Potsdam (Germany) and Department of Histology and Embryology, School of Medicine, Jinan University, No.601 Huangpu Road West, Guangzhou 510632, (P. R. China)

E-Mail yang_xuesong@126.com or E-Mail berthold.hocher@charite.de
\end{abstract}




\section{Introduction}

Excessive consumption of salt has been recognised as a major contributor towards hypertension, chronic kidney disease and cardiovascular events [1]. Salt intake has direct effects on plasma sodium concentration [2]. Sodium is an essential osmolyte for maintaining the functions of the blood and the extracellular space. In pregnancy, the balance of salt and water is critical for pregnancy induced plasma volume expansion [3]. But when dietary sodium intake exceeds the physiologic demands it can become a risk factor for cardiovascular diseases in later life [1]. Plasma osmolality is mainly determined by sodium, chloride and bicarbonate. In mammals, changes in the sodium balance may primarily result in alterations in the extracellular volume rather than in alterations of plasma osmolality or plasma sodium. Several mechanisms are involved. Sodium excretion by the kidney can vary largely. When sodium intake is higher than the output, the extracellular volume increases in parallel which may manifest in an increase of body weight. Among others, the activation of the ADH system may result in an increased extracellular volume to keep plasma osmolality constant. Other mechanisms to control sodium excretion with volume expansion may involve the renal sympathetic nerves, the ANP and BNP-systems, and renin-angiotensin-aldosterone system (RAAS). These regulating systems may be even more important during pregnancy and lactation, when the body is developing fast and depends very much on the immediate nutritional environment provided by the mother. Prenatal growth is sensitive to the direct and indirect effects of maternal dietary intake; manipulation of maternal diet can lead to behavioural and physiological changes of the offspring later in life. Offspring of mothers with excess intake of salt develops higher than average blood pressure in adulthood $[4,5]$. High salt intake in weanling DS rats modified cataract formation in association with hypertension [6]. In mammals, although most tissue morphogenesis is completed by birth, it has been found that the eye continues to adapt after birth [7]. Therefore, the effects on the eye of the developing organism observed with direct high salt intake might give a hint on how maternal diet could play an important role in early development during pregnancy. However, not much is known about how the maternal diet is influencing eye development and might be programming diseases of the eye in later life. Recent literature suggests that increased sodium intake during pregnancy affects the brain development of the offspring [8]. The eye can be seen as a highly specialized extension of the brain. Therefore, an excess maternal consumption of salt during pregnancy, which can increase plasma osmolality $[2,3,9]$, might have an impact on the normal processes of eye development.

The vertebrate eye derives of three embryonic parts: the optic vesicle (OV), the surrounding mesenchyme and the overlying surface ectoderm (SE) [10,11]. Signaling between these tissue components is thought to be of key importance for coordinating their development. The $\mathrm{OV}$ morphologically contacts the SE. This triggers a response that leads to a thickening of the ectoderm to form the lens placode, which later develops into the mature lens. While the lens placode internalizes to form the lens vesicle, the distal OV invaginates to develop into the optic cup with the inner layer developing into the neuroretina (NR) while the outer layer forms the retinal pigmented epithelium (RPE). The proximal regions of the OV shape the optic stalk that connects the retina to the brain $[12,13]$. Retinal cell differentiation proceeds in a highly conserved histogenetic order. Retinal ganglion cells are generated first, followed in overlapping phases by horizontal cells, cone photoreceptor-, amacrine-, rod photoreceptor-, bipolar cells and finally, Muller glia cells [13]. A normal migration of neural crest cells (NCCs) is vital for these developmental processes. The distribution and integration of the NCCs in ocular tissues depends on Paired box 6 (PAX6) transcription factor signalling [10]. Correct Pax 6 gene dosage is pivotal to embryonic development and maintenance in the eye [14], and mutations in this gene lead to complex ocular malformations [15]. Pax-6 expression is not only crucial to eye size but also to instruct neuron differentiation in the retina $[16,17]$. The retina is derived from the optic vesicle and later the optic cup, which originally are derived from the embryonic neural plate. HNK-1 is mainly expressed in 
migratory neural crest cells which contribute to the head mesenchyme $[18,19]$. The complex role of Pax6 in eye development is also conserved in the chick embryo [20].

Chick embryos are a widely used model for fetal programming and developmental biology studies because of their simplicity and similarity to early stage human embryos. The early chick embryos are quite sensitive to external physiochemical compounds. In contrast to the growing mammalian embryo, salt exposure to the chick embryo is a pure high salt osmolality model; in contrast to mammalians, salt can not be excreted by the chicken embryo nor is there a prominent activation of salt and osmolality regulating system such as the ADH and the RAAS system. This represents a strength and a weakness of this model. It is clearly a hyper-osmolality model with fixed osmolality, but endocrine and paracrine regulation of the osmolarity as present in mammalians is absent, because the growing embryo in the egg can not remove salt from the egg. . In this study, we investigated the effects of high salt/ high osmolality on the developing eyes in 5.5-day chick embryos, especially focusing on the development of the retina and the lens. We investigated morphology of the eye size and shape. Next we analysed Pax6, neurofilament (NF) and HNK-1 expression in control and high-salt treated 5.5-day chicks in order to evaluate the retina development in presence of high-salt treatment. To determine cell proliferation BrdU experiments were conducted and PH3 expression was analysed. Subsequently, expression of the cell cycle promoter Cyclin D was investigated. In order to analyse the role of high-salt treatment on cell death in the early period of chick retina development, we applied the TUNEL assay for detecting and quantifying apoptotic cells.

\section{Materials and Methods}

\section{Chick embryos}

Fertilized chick eggs were obtained from the Avian Farm of the South China Agriculture University. The eggs were incubated in a humidified incubator (Yiheng Instrument, Shanghai, China) at $38^{\circ} \mathrm{C}$ and $70 \%$ humidity. After 36 hour incubation, the chick eggs were removed of $2 \mathrm{ml}$ albumen and treated with $500 \mu \mathrm{l}$ three different concentrations of $\mathrm{NaCl}$ (Control, $\mathrm{n}=20 ; 280 \mathrm{mosm} / \mathrm{l}, \mathrm{n}=17 ; 300 \mathrm{mosm} / \mathrm{l}, \mathrm{n}=16$ respectively). For the control group, we injected $0.7 \% \mathrm{NaCl}$ (final osmolality of the egg is $240 \mathrm{mosm} / \mathrm{l}$ ); for the $280 \mathrm{mosm} / \mathrm{l}$ group, we injected $11.23 \% \mathrm{NaCl}$ (final osmolality of the egg is $280 \mathrm{mosm} / \mathrm{l}$ ); for the $300 \mathrm{mosm} / \mathrm{l}$ group, we injected $16.85 \% \mathrm{NaCl}$ (final osmolality of the egg is $300 \mathrm{mosm} / \mathrm{l}$ ). The treated embryos were incubated for a further 96 hours. Embryos were removed from their eggs and weighed. Surviving embryos were harvested for assessment of other parameters. All dead embryos were excluded from analysis.

Additional eggs were treated with mannitol (280 mosm/l, n=17; 300 mosm/l, n=16) instead of NaCl, to be able to differentiate between a potential osmotic effect and a direct effect of sodium. (final osmolality of the egg is $280 \mathrm{mosm} / \mathrm{l}$ respective $300 \operatorname{mosm} / \mathrm{l}$ ). For the NGF experiment, additional eggs were treated with $\mathrm{NaCl}$ (280mosm/l, $\mathrm{n}=5 ; 300$ mosm/l, $\mathrm{n}=5$ respectively). Control eggs were treated with $0.7 \% \mathrm{NaCl}(1 \mathrm{x}$, $\mathrm{n}=5$ ). As no anti-NGF antibody is suitable for immunostaining in chick retina, we analyzed the expression of NGF by using RT-PCR. For the immunohistochemistry of HNK-1 labeled neural crest cells, additional chick eggs were treated with high-salt until embryos reached HH12.

\section{Histology}

H\&E staining was performed on corresponding transverse sections of the embryo according to standard protocol. The diameter of the eye and the thickness of the retina were then measured.

\section{Eye measurements}

The eye size was measured across the transverse plane of the chick eye, straight through the center of the lens from the two outermost regions of the eye. The right eye diameter was compared to the left, which served as an internal control. For quantification size of the eye and thickness of the retina, the diameter of the eye and the thickness of the retina were quantified with Image-Pro Plus 6.0 in whole-mount pictures and sections respectively. 


\section{BrdU incorporation experiments}

To determine cell proliferation, additional eggs were treated with $\mathrm{NaCl}$ and $\mathrm{BrdU}$. BrdU stock solution $(10 \mathrm{mM})$ was administered to $\mathrm{NaCl}$-treated eggs/chick embryos 4 hours before the embryos grew to 5.5 days $(280 \operatorname{mosm} / \mathrm{l}+\mathrm{BrDu} 10 \mu \mathrm{l}, \mathrm{n}=10 ; 300 \mathrm{mosm} / \mathrm{l}+\mathrm{BrdU}, 10 \mu \mathrm{l}, \mathrm{n}=10)$. Control eggs were treated with $0.7 \%$ $\mathrm{NaCl}$ and $\mathrm{BrdU}(0.7 \% \mathrm{NaCl}+\mathrm{BrdU}, 10 \mu \mathrm{l}, \mathrm{n}=10)$. Embryos were sacrificed 4 hours later, the tissue fixed in $4 \%$ paraformaldehyde for the staining. Sections of the eye were stained with a monoclonal antibody to BrdU according to the manufacturer's instruction (Roche). Cell counts were performed from a defined area in the optic nerve region of the retina (visual field at 20x magnification). We counted BrdU-positive cells and the total cell number to calculate a proliferation index (BrdU-positive cells/total cell number).

\section{PH3}

Chick embryos were treated with $\mathrm{NaCl}$ as described. Heads of 5.5-day-old chick embryos were fixed in paraformaldehyde (PFA) and paraffin-embedded. Immunostaining of Phospho-Histone H3 (PH3) was used to determine cell proliferation in the retina. PH3 immunostaining was performed on $4 \mu \mathrm{m}$ sections using the following antibody: PH3 (1:400, DSHB, USA). The fixed chick embryos were incubated with PH3 antibody at $4{ }^{\circ} \mathrm{C}$ overnight. After extensive rinsing in PBS the embryos were incubated with alexa fluor 555 anti-rabbit IgG secondary antibody $\left(1: 1000\right.$, Invitrogen, USA) at $4^{\circ} \mathrm{C}$ for $2 \mathrm{~h}$. All the paraffin sections were later counterstained with DAPI (1:1000, Invitrogen, USA). We counted PH3 positive-cells and the total cell number to calculate a proliferation index (PH3-positive cells/total cell number).

\section{Immunohistochemistry}

Whole-mount embryo immunostaining was performed using the following antibodies: neurofilament (NF; 1:500, Invitrogen, USA), Pax6 (1:100, DSHB, USA) and HNK-1 (1:500, DSHB, USA). Briefly, the fixed chick embryos were incubated with NF, Pax6 or HNK-1 antibody at $4^{\circ} \mathrm{C}$ overnight on a shaker. After extensive rinsing in PBS the embryos were incubated with alexa fluor 555 anti-mouse IgG secondary antibody (1:1000, Invitrogen, USA) or alexa fluor 488 anti-mouse IgG secondary antibody (1:1000, Invitrogen, USA) at $4^{\circ} \mathrm{C}$ overnight on a shaker. All the embryos were later counterstained with DAPI (1:1000, Invitrogen, USA) at room temperature for 1 hour.

\section{TUNEL staining}

Heads of 5.5-day-old chicken embryos were fixed in Bouin's solution and paraffin-embedded. Sections $(4 \mu \mathrm{m})$ were deparaffinized and stained with in situ cell death detection kit (Roche) according to the manufacturer's instructions. The extent of cell death was quantified by counting TUNEL+ cells on consecutive transverse sections of treated and untreated 5.5-day chick retina. We counted TUNEL positive cells and the total cell number to calculate a proliferation index (TUNEL-positive cells/total cell number).

\section{Photography}

Following immunohistochemistry, the whole mount embryos were photographed using a stereofluorescent microscope (Olympus MVX10) associated with Olympus software package Image-Pro Plus 7.0. The embryos were then sectioned into $15 \mu \mathrm{m}$ slices using a cryostat microtome (Leica CM1900), and then photographed using an epi-fluorescent microscope (Olympus LX51, Leica DM 4000B) with a CN4000 FISH Olympus software package.

\section{RNA isolation and RT-PCR}

Total RNA was isolated from chick retina tissues using a Trizol kit (Invitrogen, USA) according to manufacture's instructions. First-Strand cDNA was synthesized to a final volume of $25 \mu \mathrm{l}$ using SuperScript RIII first-strand (Invitrogen, USA). Following reverse transcription, PCR amplification of the cDNA was performed as described previously [21, 22]. The following primers were used: NGF: CGACATCAAAGGCAAAGAG and GTCGATCCGGATAAATCTC [23]; CyclinD1: TCGGTGTCCTACTTCAAGTG and GGAGTTGTCGGTGTAAATGC [24]; GAPDH: GTCAACGGATTTGGCCGTAT and AATGCCAAAGTTGTCATGGATG [25]. PCR reactions were performed in a Bio-Rad S1000TM Thermal cycler (Bio-Rad, USA). The final reaction volume was $50 \mu \mathrm{l}$ composing of $1 \mu \mathrm{l}$ first-strand cDNA, $25 \mu \mathrm{M}$ forward primer, $25 \mu \mathrm{M}$ reverse primer, $10 \mu \mathrm{l}$ PrimeSTARTM Buffer (Mg2+ plus), $4 \mu \mathrm{l}$ dNTPs Mixture (TaKaRa, Japan), $0.5 \mu \mathrm{l}$ PrimeSTARTM HS DNA Polymerase (2.5U/ $\mu \mathrm{l} \mathrm{TaKaRa,} \mathrm{Japan),} \mathrm{and} \mathrm{RNase-free} \mathrm{water} \mathrm{to} 50 \mu \mathrm{l}$. The cDNAs were amplified for 


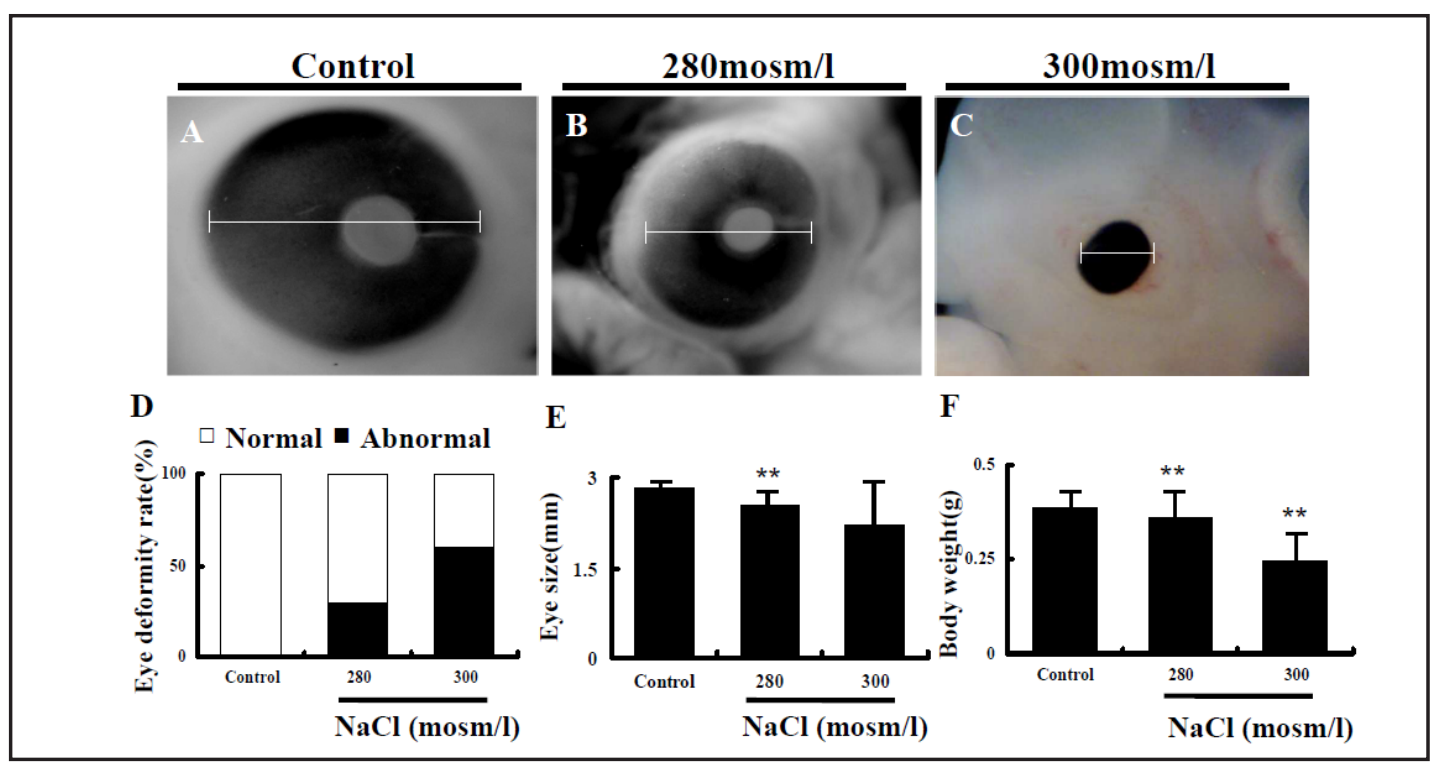

Fig. 1. Effects of high osmolarity on eye development in 5.5-day chick embryos. The size of the eye (diameter) was measured and the incidence of eye malformation documented. A-C: Representative images of eyes in 5.5-day chick embryos. The size of eye (diameter) is smaller in embryos treated with 280 or 300 mosm/l NaCl compared to control. Bar charts showing the changes in body weight (D), eye size (E), and the incidence of eye malformation (F). ${ }^{* *} \mathrm{p}<0.01$ indicate significant differences between experimental and control embryos. Scale bars $=500 \mu \mathrm{m}$ in A-C.

30 cycles. One round of amplification was performed at $94^{\circ} \mathrm{C}$ for $30 \mathrm{~s}, 30 \mathrm{~s}$ at $58^{\circ} \mathrm{C}$, and $30 \mathrm{~s}$ at $72^{\circ} \mathrm{C}$. The PCR products $(20 \mu \mathrm{l})$ were resolved in $1 \%$ agarose gels (Biowest, Spain) in $1 \times$ TAE buffer $(0.04 \mathrm{M}$ Trisacetate and 0.001 M EDTA), and 10,000x GeneGreen Nucleic Acid Dye (TIANGEN, China) solution. The resolved products were visualized in a transilluminator (SYNGENE, UK) and photographs were captured using a computerassisted gel documentation system (SYNGENE). A parallel test for GAPDH confirmed that equal amounts of RNA were used in the RT reaction.

\section{Data analysis}

Data analyses and creation of charts were performed using a Graphpad Prism 5 software package (Graphpad Software, CA, USA). The results were presented as the mean values ( $\bar{x} \pm$ SD). The value of standard deviation (SD) was presented in the error bar. All data were analyzed using ANOVA, which was employed to test the difference among the experimental groups. $\mathrm{P}<0.05$ was considered to be statistically significant.

\section{Results}

High-salt treatment causes development of eye malformations in 5.5-day chick embryos

We showed that high salt-treatment induced malformation of the eye in 5.5-day chick embryos compared with control embryos (Figs. 1A-C). The phenotype was more obvious with the higher dose of salt and the frequency of eye malformation increased with the dose (Fig. 1D). We examined transverse sections of both control and high-salt treated eyes. Measurement of the eye size (diameter) revealed that exposure to high-salt significantly decreased the size of the developing eye in 5.5-day chick embryos in comparison to controls [Fig. $1 \mathrm{E} ;$ Control $=(2.83 \pm 0.043 \mathrm{~mm}), 280 \mathrm{mosm} / \mathrm{l}=(2.54 \pm 0.060 \mathrm{~mm}), 300 \mathrm{mosm} / \mathrm{l}=(2.23$ $\left.\pm 0.198 \mathrm{~mm})\left({ }^{*} \mathrm{p}<0.05\right)\right]$. In addition, we showed that the body weight was significantly decreased with high-salt treatment [Fig. $1 \mathrm{~F}$; Control $=(0.39 \pm 0.008 \mathrm{~g}), 280 \mathrm{mosm} / \mathrm{l}=(0.36$ $\left.\pm 0.008 \mathrm{~g}), 300 \mathrm{mosm} / \mathrm{l}=(0.26 \pm 0.025 \mathrm{~g})\left({ }^{* *} \mathrm{p}<0.01\right)\right]$. 
Fig. 2. High-salt treatment impaired the development of retina and lens in 5.5-day chick embryos. H\&E staining of transverse sections of the eye (A-C). A'-C': high magnification images from the sites indicated by dotted square in A-C. D: Bar charts showing the changes in lens diameter. E: Bar charts showing the changes in the thickness of retina. ${ }^{*} \mathrm{p}<0.05$ and ${ }^{* *} \mathrm{p}<0.01$. Abbreviation: Scale bar $=500 \mu \mathrm{m}$ in A-C, $500 \mu \mathrm{m}$ in $\mathrm{A}^{\prime}-\mathrm{C}^{\prime}$.
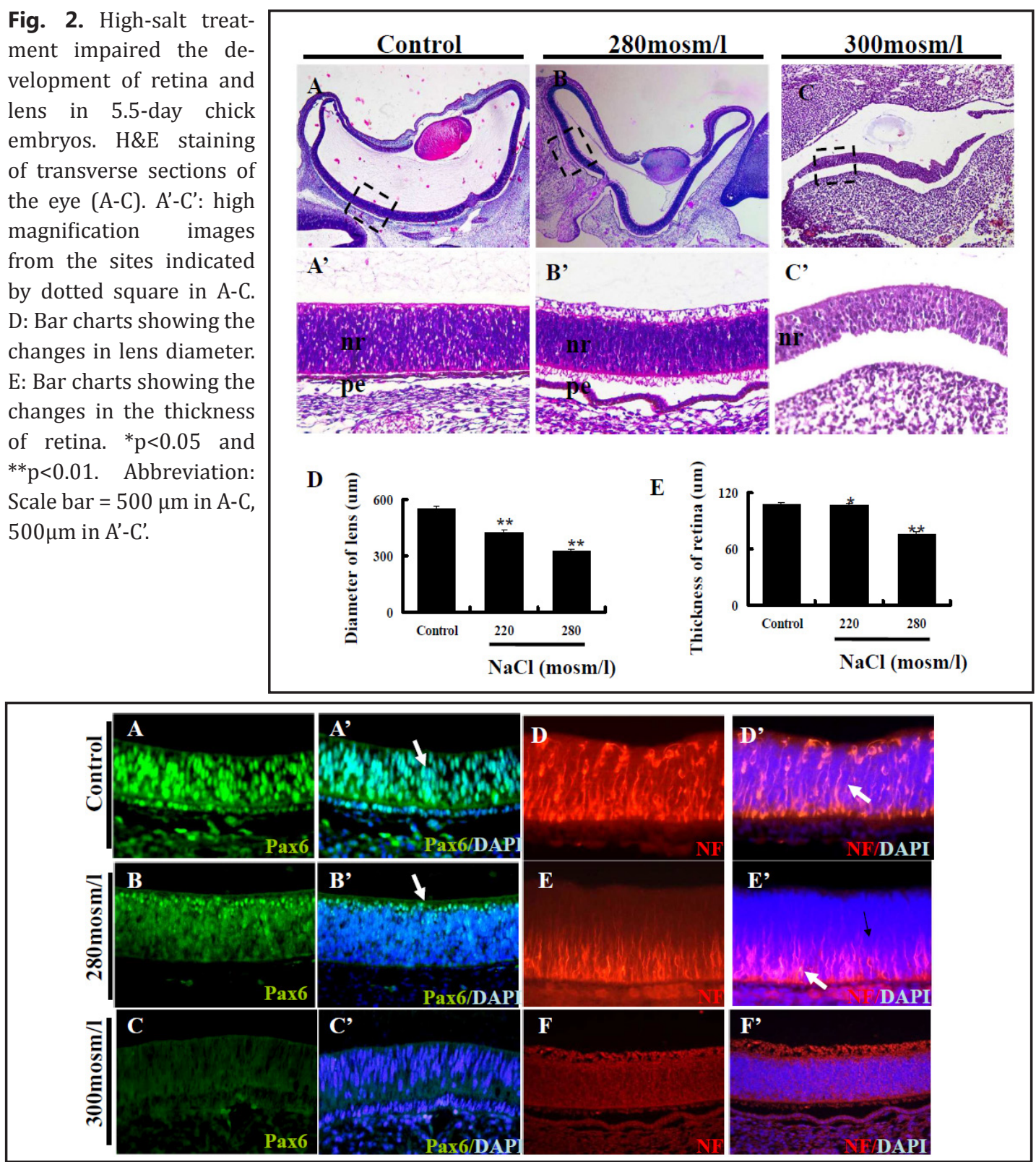

Fig. 3. High-salt treatment repressed retinal Pax6 and NF expression. A-C: Retina stained with Pax6 antibodies. A'-C': Sections were counterstained with DAPI. D-F: Retina stained with NF antibodies. NF immunostaining demonstrated the presence of neurons in the retina of controls, high-salt treatment repressed neuron development in the retina. D'-F': Sections were counterstained with DAPI. Scale bars = $60 \mu \mathrm{m}$ in A-F.

High-salt treatment affects the development of retina and lens in 5.5-day chick embryos

Morphology of the developing eye in the chick embryo was then investigated in detail by H\&E staining. The results showed that high-salt treatment impaired the development of lens and retina in 5.5-day chick eyes in a dose-dependent manner. Normally developed lenses in the control group presented in an oval shape. In high-salt treated chick embryos, the oval shape of the lens was altered or not visible at all (Figs. 2A-C). Histologic investigation of the retina also revealed distinct differences in shape and morphology between the control and high-salt treated embryos (Figs. $2 A^{\prime}-C^{\prime}$ ). High-salt treatment decreased the diameter of the lens in 5.5-day chick embryos [Fig. 2D; Control $=(547.86 \pm 9.47 \mu \mathrm{m}), 280 \mathrm{mosm} / \mathrm{l}=(422.88$ 


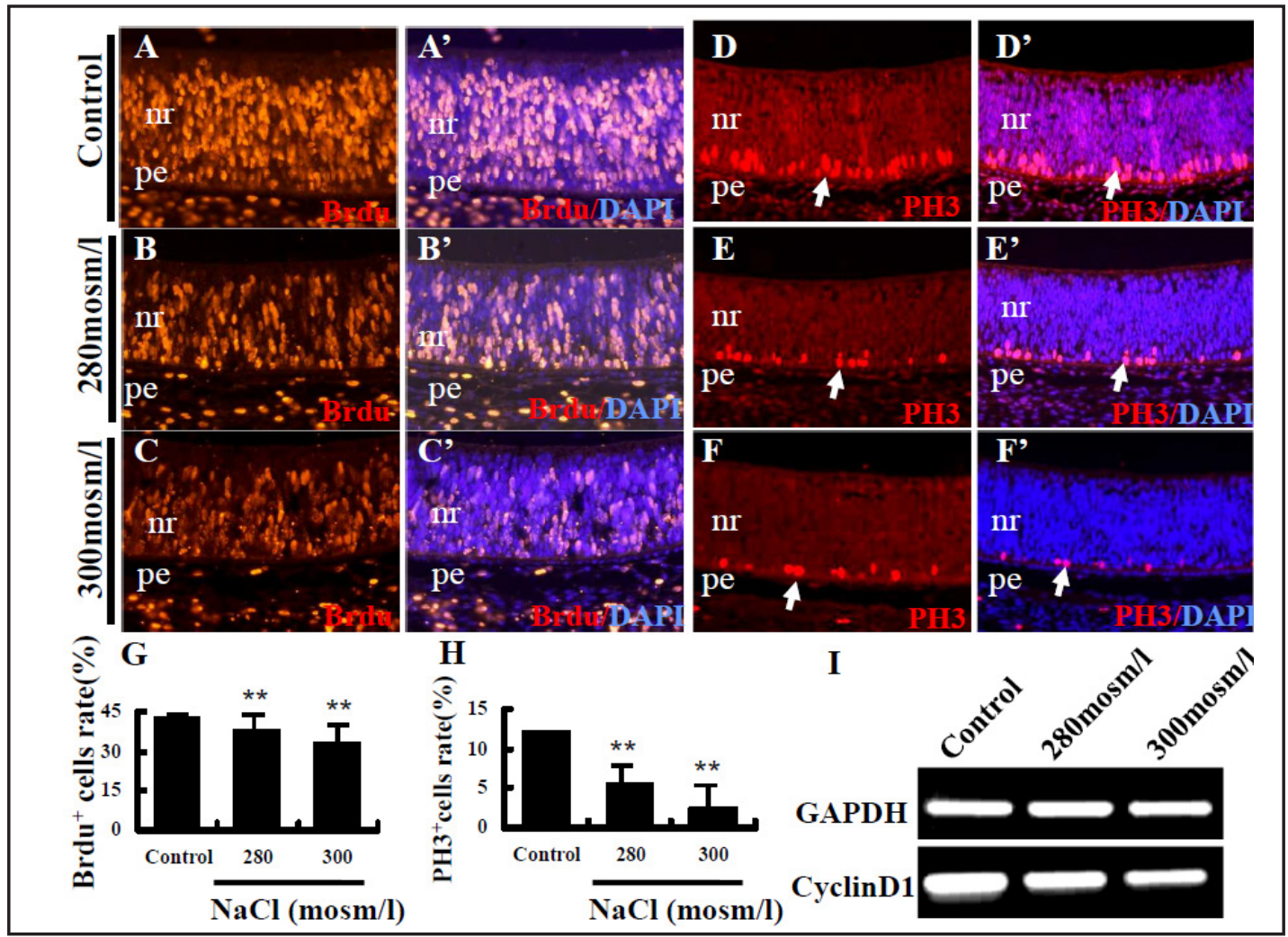

Fig. 4. High-salt treatment inhibited cell proliferation in the developing 5.5-day chick retina. BrdU and PH3 immunostaining were performed respectively in the developing chick retina following high-salt treatment. A-C: Representative images of BrdU immunofluorescent staining in 5.5-day chick embryonic retina following high-salt treatment. A'-C': The merge images of the A-C + DAPI staining. The staining showed less BrdU positive cells than in the control group. D-F: Representative images of PH3 immunofluorescent staining in 5.5-day chick embryonic retina following high-salt treatment. $\mathrm{D}^{\prime}-\mathrm{F}^{\prime}$ : The merged images of the D-F + DAPI staining. G-H: Cell proliferation rate was quantified in chick retinal sections using the BrdU assay (G) or PH3 assay $(\mathrm{H})$ respectively. ${ }^{*} \mathrm{p}<0.05$ and ${ }^{* *} \mathrm{p}<0.01$ indicate significant differences between experimental and control embryos. I: Semi-quantitative RT-PCR analysis showing cyclinD1 expression was significantly inhibited by high-salt treatment. Abbreviation: nr, neuroretina. pe, pigmented epithelium. Scale bars = $50 \mu \mathrm{m}$ in A-F.

$\left.\pm 10.54 \mu \mathrm{m}), 300 \mathrm{mosm} / \mathrm{l}=(315.13 \pm 29.76 \mu \mathrm{m})\left({ }^{*} \mathrm{p}<0.05,{ }^{* *} \mathrm{p}<0.01\right)\right]$. High-salt treatment also decreased the thickness of the retina [Fig. 2E; Control $=(109.57 \pm 3.34 \mu \mathrm{m}), 280 \mathrm{mosm} / \mathrm{l}$ $\left.=(104.50 \pm 4.75 \mu \mathrm{m}), 300 \mathrm{mosm} / \mathrm{l}=(74.25 \pm 4.67 \mu \mathrm{m})\left({ }^{*} \mathrm{p}<0.05,{ }^{* *} \mathrm{p}<0.01\right)\right]$. Similar results concerning morphological eye abnormalities were seen when applying mannitol resulting in similar changes of osmolality (data not shown).

\section{Inhibitory effects of high-salt treatment on retinal Pax6 and NF expression in 5.5-day} chick embryos

We examined the expression of Pax6 and NF in in 5.5-day chick retina by using immunostaining. We found that Pax6 expression was less pronounced with high-salt treatment in comparison to the control group (Fig. $3 \mathrm{~A}-\mathrm{C}$ ). Immunostaining also revealed that NF expression was less pronounced following high-salt treatment (Figs. 3E-F) in comparison to the control group (Fig. 3D).

High-salt treatment repressed cell proliferation in the developing 5.5-day chick retina

We performed BrdU incorporation experiments in 5.5-day chick retina in order to determine if an impaired cell proliferation was involved in the phenotypes induced by 


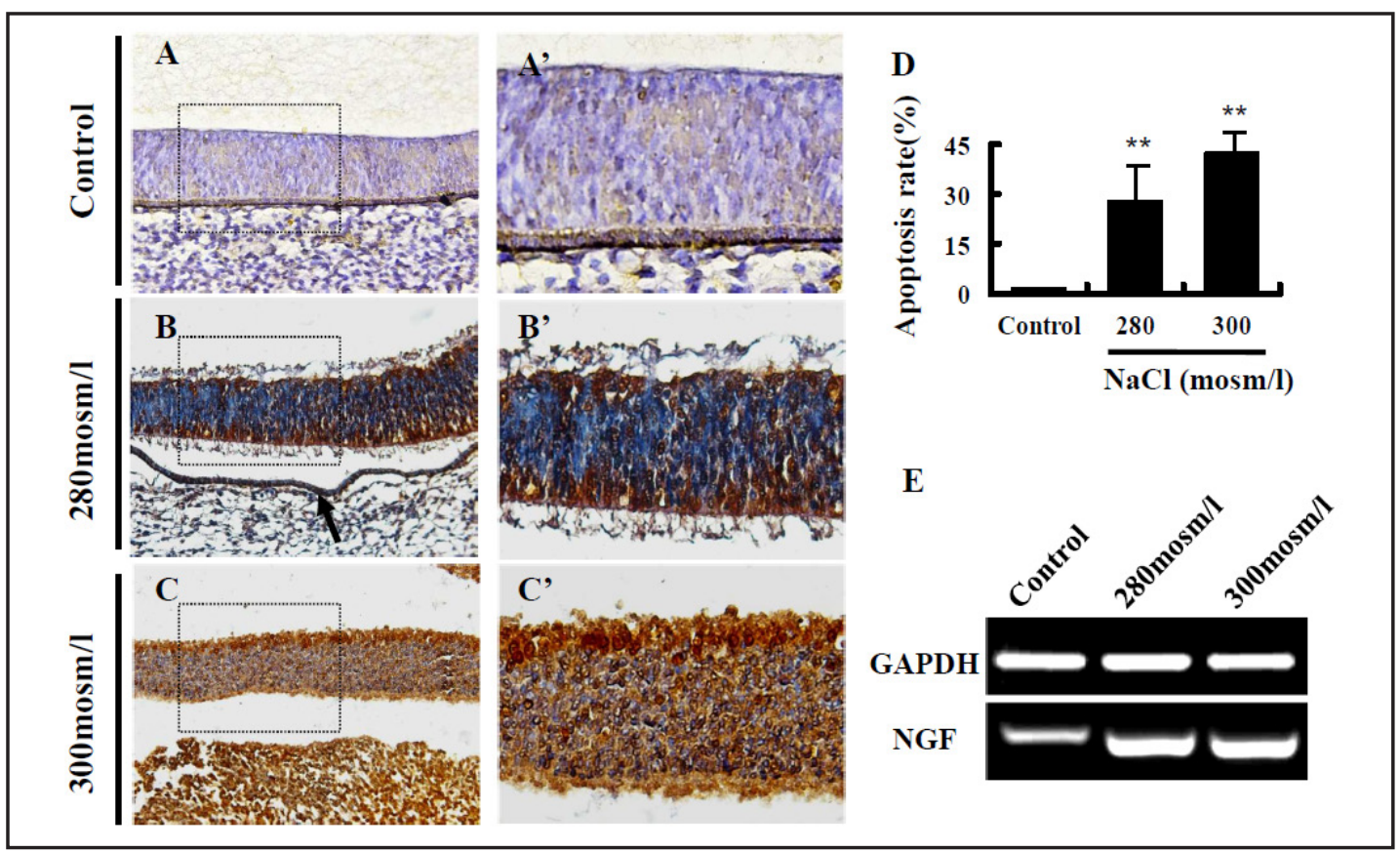

Fig. 5. High-salt treatment increased cell death in the developing chick retina. A-C: TUNEL staining and semi-quantitative RT-PCR were performed in the developing chick retina after the treatment with high-salt. Less apoptotic nuclei were labeled in control sections (A) compared with sections from high osmolarity treated embryos (B-C). A'-C': high magnification images from the squares in Figs. A-C. D: Quantification of cell death. Apoptotic rate were quantified in chick retinal sections using the TUNEL assay. ${ }^{*} \mathrm{p}<0.05$ and ${ }^{* *} \mathrm{p}<0.01$ indicate significant difference between experimental and control embryos. E: Semi-quantitative RT-PCR analysis showing NGF expression in 5.5-day chick retina was significantly increased by high osmolarity treatment. Scale bars $=50 \mu \mathrm{m}$ in A-C, $25 \mu \mathrm{m}$ in $\mathrm{A}^{\prime}-\mathrm{C}^{\prime}$.

high-salt treatment. Quantification of BrdU+ cells revealed that the BrdU+ cells rate was significantly decreased in the retina treated with high-salt compared to the control group [Fig. 4G; Control $=(43.11 \pm 0.99 \%) ,280 \mathrm{mosm} / \mathrm{l}=(37.22 \pm 0.57 \%), 300 \mathrm{mosm} / \mathrm{l}=(31.64$ $\left.\pm 0.81 \%)\left({ }^{* *} \mathrm{p}<0.01\right)\right]$. Figs. $4 \mathrm{~A}-\mathrm{C}$ are representative images which show the difference between control and high-salt treated embryos in retinal BrdU incorporation.

Immunostaining for $\mathrm{PH} 3$ showed a reduction in $\mathrm{PH} 3$ positive cells in the retina of 5.5-day chick embryos [Fig. $4 \mathrm{H}$; Control $=(7.88 \pm 0.52 \%), 280 \mathrm{mosm} / \mathrm{l}=(4.11 \pm 0.48 \%), 300 \mathrm{mosm} / \mathrm{l}$ $=(2.44 \pm 0.34 \%)]$. Figs. $4 \mathrm{D}-\mathrm{F}$ are representative images which show the difference between control and high-salt treated embryos in retinal PH3+ cell expression. We also analysed the expression of Cyclin D1 using RT-PCR. The results indicated that the expression of CyclinD1 was apparently reduced by high-salt treatment. (Fig. 4I).

\section{High-salt treatment increases apoptosis in the developing 5.5-day chick retina}

The extent of cell death was quantified by TUNEL staining of consecutive retinal transverse sections of treated and untreated 5.5-day chick embryos. The number of TUNELpositive cells in the retina of embryos treated with high-salt was significantly higher than in controls [Fig. 5D; Control $=(1.43 \pm 0.30 \%), 280 \mathrm{mosm} / \mathrm{l}=(24.88 \pm 1.08 \%), 300 \mathrm{mosm} / \mathrm{l}=$ $\left.(41.75 \pm 1.22 \%)\left({ }^{* *} \mathrm{p}<0.01\right)\right]$.

TUNEL-positive nuclei were localized across the neuroepithelium and the positive cells were more abundant in the inner half of the retina. Figs. 5A-C are representative images which show the difference between control and high-salt treated embryos in retinal TUNEL+ cell expression. Figs. $A^{\prime}-C^{\prime}$ are high magnification images from the squares in Figs. A-C.

RT-PCR analysis showed that NGF expression in 5.5-day chick retina was significantly increased by high-salt treatment (Fig. 5E). 
Fig. 6. High-salt treatment inhibited the development of 5.5-day chick lens and the expression of Pax6 in chick lens. A-C: Transverse sections of lens stained with H\&E from control and high-salt treated embryos. A'-C': Immunostaining with Pax6 (enlargement of framed regions in A-C), showed that high-salt treatment repressed the expression of Pax6 in chick lens. $A^{\prime \prime}-C^{\prime \prime}$ : The sections in $A^{\prime}-C^{\prime}$ were counterstained with DAPI. Scale bars $=60 \mu \mathrm{m}$ in $\mathrm{A}-\mathrm{C}$, $30 \mu \mathrm{m}$ in $A^{\prime}-C^{\prime}$ and $A^{\prime \prime}-C^{\prime \prime}$.

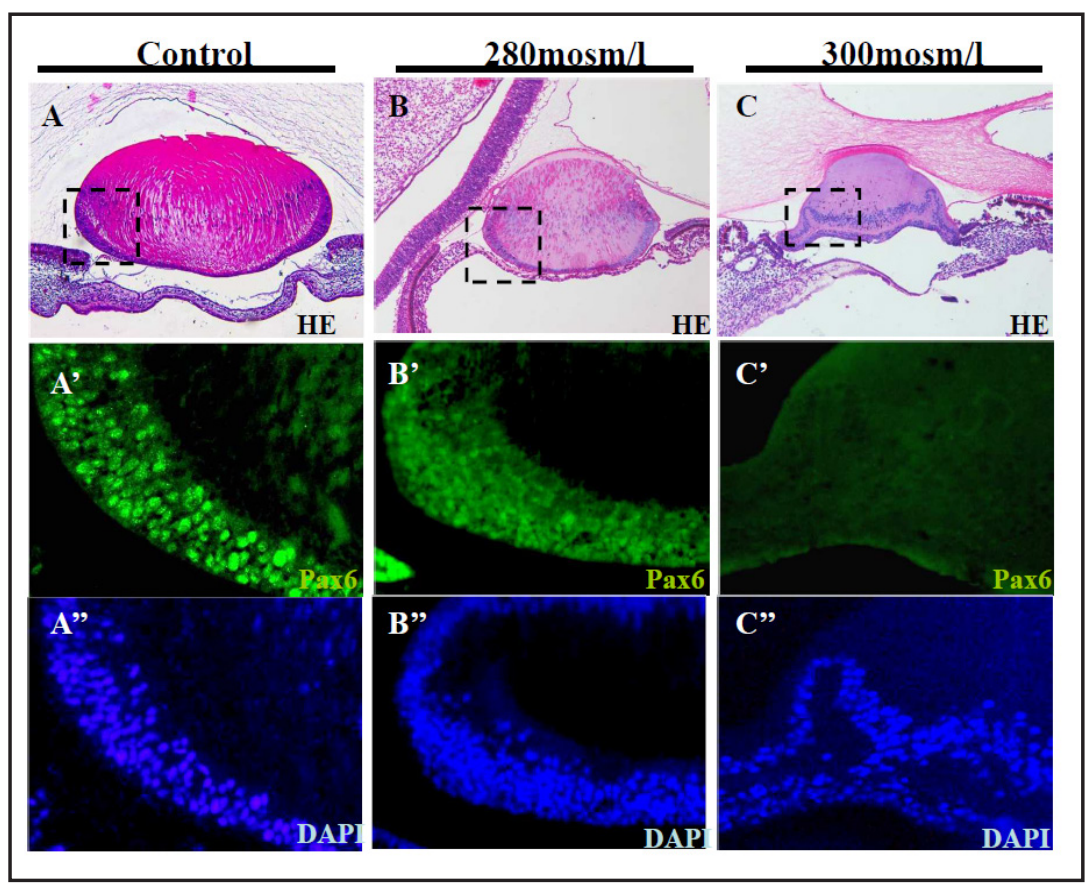

Effects of high-salt treatment on Pax6 expression in developing 5.5-day chick lens

Lens morphology was shown by H\&E staining. Transverse sections of the control group showed oval shaped lenses, whereas the lenses of high salt-treated embryo eyes were abnormally shaped, smaller, or not visible at all. The effects on lens morphology were dose-dependent (Figs. 6 A-C). Expression of Pax6 in the lens was investigated by using immunostaining. Pax6 was expressed in the nucleus of fiber cells in 5.5day chick lens (Figs. $\left.6 A^{\prime}-A^{\prime \prime}\right)$ of control embryos. In contrast, only weak Pax6 staining was detected in $280 \mathrm{mosm} / \mathrm{l}$ osmolarity-treated fiber cells and no Pax6 staining was found in $300 \mathrm{mosm} / \mathrm{l}$ osmolaritytreated fiber cells (Figs. $\mathrm{A}^{\prime}-\mathrm{C}^{\prime}$ are enlarged images of framed regions in $\mathrm{A}-\mathrm{C}$ ). $\mathrm{A}^{\prime \prime}-\mathrm{C}^{\prime \prime}$ : The same sections were counterstained with DAPI.

Inhibitory effects of high-salt treatment on HNK-1 labeled neural crest cell delamination in the early chick embryos

HNK-1 expression was investigated in HH13 chick embryos at the edge of the optic cup by immunostaining. HNK-1+ cells were evident at the edge of the optic cup. HNK-1 expression was significantly inhibited by high-salt treatment in comparison to the control group (Fig. $\left.7 A^{\prime}-C^{\prime}\right)$. The difference between the control and the high-salt treated group appeared to be more obvious when looking at the corresponding transverse sections (Fig. 7D-F'”).

\section{Discussion}

Intrauterine environments are closely related to fetal development and postnatal health. A diet high in salt is typical for modern societies and can lead to high blood pressure, cardiovascular diseases, and neurovascular diseases [1]. Overconsumption of salt during pregnancy might also have adverse impacts on fetal development. Shin et al. recently showed that excessive maternal sodium intake in pregnant rats during the last week of gestation affects the neural development in the rat offspring. In the cerebral cortex and hippocampus of the offspring, proteins important for the progress of neural development were decreased or aberrantly expressed. The effects on eye development however, were not investigated. As the eye is essentially a highly specialized extension of the brain, we decided to investigate the effect of salt-loading/treatment on eye development with special focus on the developing 


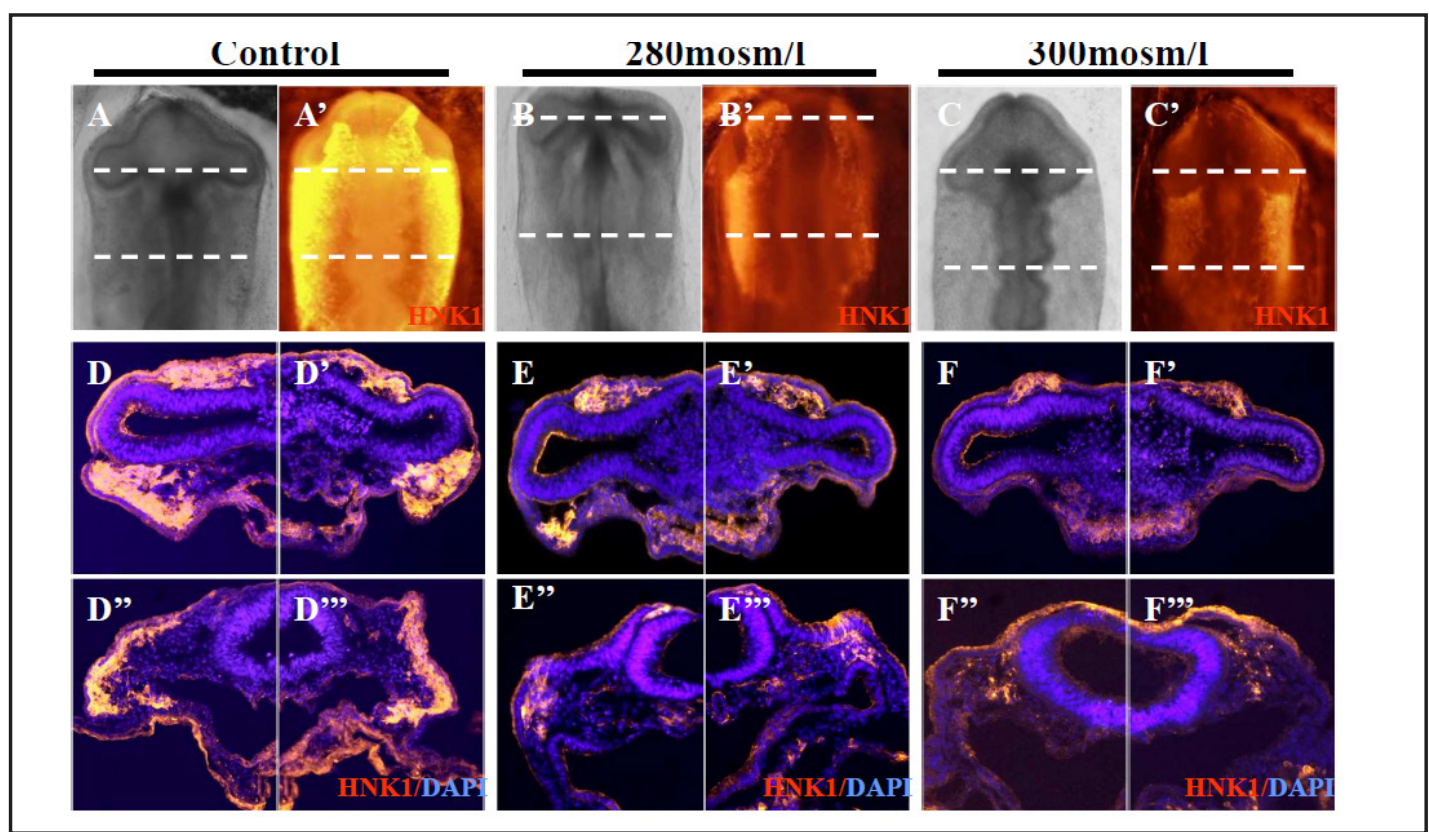

Fig. 7. High-salt treatment adversely affected HNK-1 labeled neural crest cell migration in early chick embryo. Fertilized chick eggs were treated with high-salt until embryos reached HH12, then immunofluorescence staining with HNK-1 antibody was performed. Representative images of HH12 chick embryos (A-C) following high-salt treatment and immunostaining with HNK-1 ( $\left.A^{\prime}-C^{\prime}\right)$. D-D' are transverse sections of the anterior regions of HNK-1 stained embryos as indicated by the dotted black lines in A'. D"-D"' are transverse sections of the posterior region in A'. E-E' are transverse sections of the anterior regions of HNK-1 stained embryos as indicated by the dotted black lines in B'. E'-E'"' are transverse sections of the posterior region in B'. F-F' are transverse sections of the anterior regions of HNK-1 stained embryos as indicated by the dotted black lines in C'. F"'-F'" are transverse sections of the posterior region in C'. Scale bars $=300 \mu \mathrm{m}$ in A-C and $\mathrm{A}^{\prime}-\mathrm{C}^{\prime}, 100 \mu \mathrm{m}$ in D-F"'.

retina and lens. As a model for the experiment we chose the early chick embryo model because it corresponds to the first month of embryonic development in mammals with an eye structure that is big in size in proportion to the embryos body [26, 27].

We showed that high salt-treatment induced malformation of the eye in 5.5-day chick embryos compared with control embryos. It led to a reduction in eye size and other morphological abnormalities. Thickness of the retina and size and shape of the lens were distinctly affected.

The range of eye defects and anomalies we observed in the high-salt treated chick embryos, are resembling those seen after mutations of the pattern formation gene Paired box gene 6 (Pax6). Pax6 is a master control gene in eye development that specifies important developmental processes in the eye [28]. The optic system develops primarily from three embryonic parts: the optic vesicle, the surrounding mesenchyme and the overlying surface ectoderm [10]. While the retina arises from the central nervous system, the lens originates from the surface ectoderm [12]. Pax6 is expressed dynamically during the early development of the eye in both, the surface ectoderm and the optic vesicle, which integrate to generate the structures of the eye [29]. As morphogenesis proceeds, Pax6 is expressed in the lens, retinal pigment epithelium and retina [29]. In humans with mutations in Pax6, microphthalmia, aniridia [30, 31] and pan-ocular disorders are observed [32]. Loss of Pax6 function leads to an eyeless phenotype in mice $[33,34]$. When periocular mesenchyme cells, originating from the neural crest and expressing Pax-6, are experimentally reduced, this leads to 
anterior eye defects in the chick eye morphogenesis [20]. We could show that retinal Pax6 expression was impaired in high salt-treated chick embryos. As mentioned, Pax6 plays also a role in subsequent steps of retinogenesis [10]. This may be an explanation for the observed reduction of the retina thickness. As Pax6 plays an important role in the neuron formation of retina [35], the impaired expression of this gene might have contributed to the observed reduction in the retinal nerve development (shown by reduced NF immunostaining signals compared and restricted distribution of NF-positive cells).

Another explanation could be that high salt-treatment impaired the retinal cell proliferation. The phosphorylation of PH3 only occurs in cells undergoing mitosis, which makes PH3 a good marker for proliferating cells. High-salt treatment caused a reduction in PH3 positive cells in the retina in 5.5-day chick embryos. The reduction of cell proliferation was also confirmed by BrdU incorporation experiments. Cell cycle gene signaling was investigated to better understand the mechanisms of the decrease in proliferation of retinal cells. PCR results showed that CyclinD1expression was apparently reduced by high-salt treatment. During the cell cycle, the G1/S phase depends on cyclin D1. Thus, a decrease in cyclin D1 might have contributed to reduced cell proliferation by mechanisms of cell cycle arrest. Hyperosmolarity can activate the G2/M checkpoint through p38 activation, which causes a drop in the cyclin-dependent kinase 2 activity [36].

Another potential mechanism that might have led to high-salt induced retinal phenotype could have been apoptosis. In fact, the retina from the embryos treated with highsalt showed a remarkable increase of apoptotic cells in comparison with those of control embryos (indicated by the TUNEL assay). Interestingly, NGF expression was increased in a corresponding manner to TUNEL.

It is well known that neuronal survival depends on the capability of their axons to compete for limiting amounts of neurotrophic input from the target area, whereas lack of neurotrophic support results in cell death [37]. The role of NGF is mostly interpreted as a trophic factor that promotes innervation [38]. However, previous studies suggest that NGF could also act as a pro-apoptotic molecule and therefore could induce cell death in the nervous system $[39,40]$.

In the presence of high-salt, the size of the lens was obviously smaller and abnormally shaped compared with the control group. We could show that Pax6 expression in the developing lens of high-salt treated 5.5-day chick embryos was impaired. Recent studies have revealed that Pax6 mediates two sequential steps during early lens development: lensbias and lens-specification [10]. Thus, we speculate that repression of the Pax6 expression in the lens by high-salt treatment might have led to the observed lens phenotype.

Neural crest cells (NCC) are very important as key organizers of the vertebrate eye by contributing to the alignment of lens and retina and by patterning the optic vesicle $[41,42]$.Therefore, we performed immunostaining for HNK-1+ neural crest cells. HNK1 expression at the optic vesicle level in HH12 chick embryos was significantly inhibited by the treatment with high-salt. Bailey et al. previously reported that loss of NCCs leads to precocious/ectopic lens differentiation [43]. The distribution and integration of the NCCs in ocular tissues depends on PAX6 transcription factor signalling. In vitro experiements with rat NCCs exposed to teratogenic glucose concentrations found a decreased Pax-6 expression, suggesting that Pax-6 expression is impaired in the presence of high osmolarity [44]. As we also saw a decreased expression of PAX6 in the lens, this could have led to an impaired migration of NCCs which may have not been sufficient to initiate normal lens development.

We hypothesize that the molecular mechanisms during embryogenesis linking reduced PAX6 expression, high salt exposure/increased osmolality with eye abnormalities might be due to epigenetic alterations affecting the transcription of the PAX6 gene, for example an altered methylation of the PAX6 gene promoter region causing a decrease in PAX6 gene expression [45]. Further studies need to address the presumably epigenetic mechanisms explaining our observations. 


\section{Study limitations}

The chosen model does not directly reflect the environment and conditions of a developing human embryo. Therefore, it is not possible to simply extend and apply the results observed in chick embryos to humans. However, much of what we know regarding morphogenesis including craniofacial development, was first established with avian models [46]. Importantly, the chick embryo model has the advantage of allowing the investigation of potentially hazardouse substances directly on the embryo.

\section{Conclusion}

In this study, we investigated the effects of high-salt/high osmolality on the developing eyes in chick embryos, especially focusing on the development of the retina and the lens. We showed that high salt-treatment induced malformation of the eye in 5.5-day chick embryos compared with control embryos. It led to a reduction in eye size and other morphological abnormalities. Thickness of the retina and size and shape of the lens were distinctly affected. The observed changes of eye morphology induced by high-salt treatment might have been partially caused by a decrease in PAX6 gene expression.

\section{Acknowledgements}

This study was supported by "973 Project" (2010CB529703); NSFC grant (31071054, 30971493) and Guangdong Natural Science Foundation (S2011010001593, S2013010013392) to X Yang. Also part funded by the Fundamental Research Funds for the Central Universities (21614319) to G Wang.

\section{References}

-1 Appel LJ, Frohlich ED, Hall JE, Pearson TA, Sacco RL, Seals DR, Sacks FM, Smith SC Jr, Vafiadis DK, Van Horn LV: The importance of population-wide sodium reduction as a means to prevent cardiovascular disease and stroke: A call to action from the american heart association. Circulation 2011;123:1138-1143.

-2 He FJ, Markandu ND, Sagnella GA, de Wardener HE, MacGregor GA: Plasma sodium: Ignored and underestimated. Hypertension 2005;45:98-102.

-3 Recommendations for routine blood pressure measurement by indirect cuff sphygmomanometry. American society of hypertension. Am J Hypertens 1992;5:207-209.

4 Porter JP, King SH, Honeycutt AD: Prenatal high-salt diet in the sprague-dawley rat programs blood pressure and heart rate hyperresponsiveness to stress in adult female offspring. Am J Physiol Regul Integr Comp Physiol 2007;293:R334-342.

5 Contreras RJ, Wong DL, Henderson R, Curtis KS, Smith JC: High dietary nacl early in development enhances mean arterial pressure of adult rats. Physiol Behav 2000;71:173-181.

6 Rodriguez-Sargent C, Estape ES, Rodriguez-Santiago A, Ramos VL, Irizarry JE, Cangiano JL, MartinezMaldonado M: Lenticular rubidium uptake and plasma renin activity in weanling cataract-prone saltsensitive rats. Hypertension 1990;15:I144-148.

7 Bourne JA: Unravelling the development of the visual cortex: Implications for plasticity and repair. J Anat 2010;217:449-468.

$>8$ Shin JA, Ahn YM, Lee HA, Park H, Kim YJ, Lee HY: Effect of maternal excessive sodium intake on postnatal brain development in rat offspring. Nutr Neurosci 2014. http://dx.doi.org/10.1179/147683051 3Y.0000000102.

-9 Davison JM, Vallotton MB, Lindheimer MD: Plasma osmolality and urinary concentration and dilution during and after pregnancy: Evidence that lateral recumbency inhibits maximal urinary concentrating ability. Br J Obstet Gynaecol 1981;88:472-479. 


\section{Cellular Physiology Cell Physiol Biochem 2014;34:804-817 and Biochemistry

10 Ashery-Padan R, Gruss P: Pax6 lights-up the way for eye development. Curr Opin Cell Biol 2001;13:706714.

11 Dyer MA, Cepko CL: Regulating proliferation during retinal development. Nat Rev Neurosci 2001;2:333342.

$>12$ Chow RL, Lang RA: Early eye development in vertebrates. Annu Rev Cell Dev Biol 2001;17:255-296.

$\checkmark 13$ Young RW: Cell proliferation during postnatal development of the retina in the mouse. Brain Res 1985;353:229-239.

14 Gregory-Evans CY, Wang X, Wasan KM, Zhao J, Metcalfe AL, Gregory-Evans K: Postnatal manipulation of pax6 dosage reverses congenital tissue malformation defects. J Clin Invest 2014;124:111-116.

15 Canto-Soler MV, Adler R: Optic cup and lens development requires pax6 expression in the early optic vesicle during a narrow time window. Dev Biol 2006;294:119-132.

-16 Berninger B, Costa MR, Koch U, Schroeder T, Sutor B, Grothe B, Gotz M: Functional properties of neurons derived from in vitro reprogrammed postnatal astroglia. J Neurosci 2007;27:8654-8664.

17 Heins N, Malatesta P, Cecconi F, Nakafuku M, Tucker KL, Hack MA, Chapouton P, Barde YA, Gotz M: Glial cells generate neurons: The role of the transcription factor pax6. Nat Neurosci 2002;5:308-315.

18 Graw J: Genetic aspects of embryonic eye development in vertebrates. Dev Genet 1996;18:181-197.

19 Graw J: Eye development. Curr Top Dev Biol 2010;90:343-386.

20 Hsieh YW, Zhang XM, Lin E, Oliver G, Yang XJ: The homeobox gene six3 is a potential regulator of anterior segment formation in the chick eye. Dev Biol 2002;248:265-280.

21 Dugaiczyk A, Haron JA, Stone EM, Dennison OE, Rothblum KN, Schwartz RJ: Cloning and sequencing of a deoxyribonucleic acid copy of glyceraldehyde-3-phosphate dehydrogenase messenger ribonucleic acid isolated from chicken muscle. Biochemistry 1983;22:1605-1613.

22 Maroto M, Reshef R, Munsterberg AE, Koester S, Goulding M, Lassar AB: Ectopic pax-3 activates myod and myf-5 expression in embryonic mesoderm and neural tissue. Cell 1997;89:139-148.

23 Dunker N, Schuster N, Krieglstein K: Tgf-beta modulates programmed cell death in the retina of the developing chick embryo. Development 2001;128:1933-1942.

24 Scott-Drechsel DE, Rugonyi S, Marks DL, Thornburg KL, Hinds MT: Hyperglycemia slows embryonic growth and suppresses cell cycle via cyclin d1 and p21. Diabetes 2013;62:234-242.

-25 Huber K, Franke A, Bruhl B, Krispin S, Ernsberger U, Schober A, von Bohlen und Halbach O, Rohrer H, Kalcheim C, Unsicker K: Persistent expression of bmp-4 in embryonic chick adrenal cortical cells and its role in chromaffin cell development. Neural Dev 2008;3:28.

26 Ma ZL, Wang G, Cheng X, Chuai M, Kurihara H, Lee KK, Yang X: Excess caffeine exposure impairs eye development during chick embryogenesis. J Cell Mol Med 2014;18:1134-1143.

27 Tufan AC, Abban G, Akdogan I, Erdogan D, Ozogul C: The effect of in ovo ethanol exposure on retina and optic nerve in a chick embryo model system. Reprod Toxicol 2007;23:75-82.

-28 Puk O, Yan X, Sabrautzki S, Fuchs H, Gailus-Durner V, Hrabe de Angelis M, Graw J: Novel small-eye allele in paired box gene 6 (pax6) is caused by a point mutation in intron 7 and creates a new exon. Mol Vis 2013;19:877-884.

29 Manuel M, Pratt T, Liu M, Jeffery G, Price DJ: Overexpression of pax6 results in microphthalmia, retinal dysplasia and defective retinal ganglion cell axon guidance. BMC Dev Biol 2008;8:59.

-30 Sonoda S, Isashiki Y, Tabata Y, Kimura K, Kakiuchi T, Ohba N: A novel pax6 gene mutation (p118r) in a family with congenital nystagmus associated with a variant form of aniridia. Graefes Arch Clin Exp Ophthalmol 2000;238:552-558.

-31 Xiao X, Li S, Zhang Q: Microphthalmia, late onset keratitis, and iris coloboma/aniridia in a family with a novel pax6 mutation. Ophthalmic Genet 2012;33:119-121.

-32 Shaham 0, Menuchin Y, Farhy C, Ashery-Padan R: Pax6: A multi-level regulator of ocular development. Prog Retin Eye Res 2012;31:351-376.

33 Halder G, Callaerts P, Gehring WJ: Induction of ectopic eyes by targeted expression of the eyeless gene in drosophila. Science 1995;267:1788-1792.

-34 Hill RE, Favor J, Hogan BL, Ton CC, Saunders GF, Hanson IM, Prosser J, Jordan T, Hastie ND, van Heyningen V: Mouse small eye results from mutations in a paired-like homeobox-containing gene. Nature 1991;354:522525. 
-35 Haubst N, Berger J, Radjendirane V, Graw J, Favor J, Saunders GF, Stoykova A, Gotz M: Molecular dissection of pax6 function: The specific roles of the paired domain and homeodomain in brain development. Development 2004;131:6131-6140.

-36 de Nadal E, Alepuz PM, Posas F: Dealing with osmostress through map kinase activation. EMBO Rep 2002;3:735-740.

-37 Hamburger V: History of the discovery of neuronal death in embryos. J Neurobiol 1992;23:1116-1123.

-38 Levi-Montalcini R: The nerve growth factor 35 years later. Science 1987;237:1154-1162.

-39 Muragaki Y, Chou TT, Kaplan DR, Trojanowski JQ, Lee VM: Nerve growth factor induces apoptosis in human medulloblastoma cell lines that express trka receptors. J Neurosci 1997;17:530-542.

40 Bono F, Lamarche I, Bornia J, Savi P, Della Valle G, Herbert JM: Nerve growth factor (ngf) exerts its proapoptotic effect via the p75ntr receptor in a cell cycle-dependent manner. FEBS Lett 1999;457:93-97.

41 Watabe T, Miyazono K: Roles of tgf-beta family signaling in stem cell renewal and differentiation. Cell Res 2009;19:103-115.

42 Beebe DC, Coats JM: The lens organizes the anterior segment: Specification of neural crest cell differentiation in the avian eye. Dev Biol 2000;220:424-431.

43 Bailey AP, Bhattacharyya S, Bronner-Fraser M, Streit A: Lens specification is the ground state of all sensory placodes, from which fgf promotes olfactory identity. Dev Cell 2006;11:505-517.

44 Wentzel P, Eriksson UJ: Altered gene expression in rat cranial neural crest cells exposed to a teratogenic glucose concentration in vitro: Paradoxical downregulation of antioxidative defense genes. Birth Defects Res B Dev Reprod Toxicol 2011;92:487-497.

45 Hocher B: More than genes: The advanced fetal programming hypothesis. J Reprod Immunol 2014.

46 Smith SM: The avian embryo in fetal alcohol research. Methods Mol Biol 2008;447:75-84. 